\title{
O dispositivo formativo da residência pedagógica: ataques, lutas e resistências
}

\author{
Flávia Cristina de Macêdo Santana' (DD \\ Jonei Cerqueira Barbosa" (D)
}

RESUMO

Este artigo teve por objetivo analisar como a implementação do Programa Residência Pedagógica (PRP) fortalece determinadas linhas de força no dispositivo formativo da residência pedagógica. Para tanto, mobilizamos algumas ferramentas conceituais propostas por Foucault. Optamos pela análise documental de um corpus constituído de portarias, editais e manifestos de entidades, os quais nos deram indícios sobre quais linhas de força do dispositivo são reforçadas com a implementação do programa. Diante disso, tomamos como referência cinco pontos de ancoragem: o duelo entre teoria e prática; a reformulação do estágio; a relação universidade e escola; a associação do PRP à Base Nacional Comum Curricular; e a autonomia das instituições formadoras. De maneira geral, os modos de resistência operacionalizados atravessaram o dispositivo colocando em relevo quatro estratégias: acusação, rejeição, restrição e repúdio. Essa análise microssocial sugere a reestruturação do programa, para que seu discurso seja legitimado.

\section{PALAVRAS-CHAVE}

formação de professores; residência pedagógica; dispositivo. 


\title{
THE PEDAGOGICAL RESIDENCY TRAINING DEVICE: ATTACKS, STRUGGLES AND RESISTANCE
}

\begin{abstract}
This paper aimed to analyze how the implementation of the Pedagogical Residency Program (PRP) strengthens certain lines of force in the Pedagogical Residency training device. For this purpose, we mobilized some conceptual tools proposed by Foucault. We opted for the documental analysis of a corpus consisting of ordinances, edicts, and the manifestos of entities, which gave us clues as to which lines of force of the device are reinforced with the implementation of the Program. Given this, five anchor points are taken as reference, namely: the duel between theory and practice; the reformulation of the internship; the university and school relationship; the association of the PRP with the National Common Curricular Base and the autonomy of the educational institutions. In general, the modes of operationalized resistance crossed the device, highlighting four strategies: accusation, rejection, restriction, and repudiation. This microsocial analysis suggests a restructuring of the Program so that its discourse can be legitimized.
\end{abstract}

KEYWORDS

teacher training; pedagogical residency; device.

\section{EL DISPOSITIVO DE FORMACIÓN DE LA RESIDENCIA PEDAGÓGICA: ATAQUES, LUCHA Y RESISTENCIA}

\section{RESUMEN}

Este artículo tiene como objetivo analizar cómo la implementación del Programa de Residencia Pedagógica (PRP) fortalece ciertas líneas de fuerza en el dispositivo formativo de la Residencia Pedagógica. Para ello, movilizamos algunas herramientas conceptuales propuestas por Foucault. Optamos por el análisis documental de un corpus consistente en ordenanzas, avisos y los manifiestos de entidades, lo que nos dio pistas sobre qué líneas de fuerza del dispositivo de residencia pedagógica se refuerzan con la implementación del Programa. Por lo tanto, hacemos referencia a cinco puntos de anclaje, a saber: el duelo entre la teoría y la práctica; la reformulación de la pasantía; la relación entre la universidad y la escuela; la asociación de PRP al Base Curricular Nacional Común y la autonomía de las instituciones de formación. En general, los modos de resistencias operativas cruzaron el dispositivo colocando cuatro estrategias en alivio: enjuiciamiento, rechazo, restricción y repudio. Este análisis microsocial sugiere una reestructuración del Programa para que su discurso pueda ser legitimado.

PALABRAS CLAVE

formación del profesorado; residencia pedagógica; dispositivo. 


\section{INTRODUÇÃO}

A formação inicial e continuada de professores vem se constituindo como uma dimensão-chave nas pesquisas sobre políticas públicas que legitimam ações que articulam universidade e escola (Ball e Mainardes, 2011; Barbosa e Fernandes, 2017). Essas discussões ganharam espaço com o Plano de Desenvolvimento da Educação (PDE) por meio de dois pilares: a formação de professores em suas variantes institucionais e a valorização dos profissionais da educação (Brasil, 2007), bem como com o Plano Nacional de Educação (PNE), ao definir suas metas (Brasil, 2014).

Segundo Dourado (2007, p. 922), o que se evidencia nessas políticas são "marcos regulatórios frutos de orientações, compromissos e perspectivas, em escala nacional e mundial, preconizados, entre outros, por agências e/ou organismos multilaterais e fortemente assimilados e/ou naturalizados pelos gestores de políticas públicas". Podemos tomar como exemplo os programas de iniciação à docência, tal qual acontecem em países como Estados Unidos e do Reino Unido (Berry et al., 2008).

No Brasil, nesse contexto regulatório, o Programa Residência Pedagógica (PRP), instituído pela Coordenação de Aperfeiçoamento de Pessoal de Nível Superior (CAPES), por intermédio da Portaria no 38/2018, passou a integrar a política de formação de professores (Brasil, 2018b). A nosso ver, esse programa emerge em um cenário político conturbado e reflete fragmentações, reformas educacionais, mudanças incoerentes e contraditórias. Segundo Silva (2018, p. 309), essa turbulência tem provocado "embates nas ações e Programas de formação de professores e que estes envolvem pesquisadores, movimentos sociais e entidades contra as ações de adesão do governo a uma política neoliberal e influenciada por organismos internacionais".

O programa a que nos referimos é operado por instituições de ensino superior, a fim de desenvolver atividades que se configuram em ambientação, imersão e regência, nos mesmos espaços em que são desenvolvidas atividades do Programa Institucional de Bolsas de Iniciação à Docência (PIBID) e do componente estágio supervisionado, presentes nos cursos de licenciatura. Segundo Pimenta e Lima (2017), as escolas públicas têm sido sobrecarregadas e precisam dar conta não apenas das obrigações inerentes à instituição, mas também submeter-se a outras demandas impostas pelo governo, a exemplo das avaliações institucionais e das avaliações externas.

Segundo Cosenza (2018), ainda que o interesse na formação de professores tenha aumentado nos últimos 20 anos, desde 2016, após o golpe, a lógica do Ministério de Educação (MEC), de negação do Plano Nacional de Educação (PNE) e das Diretrizes Curriculares Nacionais (DCNs), tem caminhado no sentido oposto às necessidades da formação de professores. Para a autora, desde 2018, há uma tentativa de articulação da política de formação docente do MEC com à controversa Base Nacional Comum Curricular (BNCC) $)^{1}$, como posto no próprio Edital CA-

1 É um documento de caráter normativo que define o conjunto orgânico e progressivo de aprendizagens essenciais que todos os alunos devem desenvolver ao longo das etapas e modalidades da educação básica, de modo que tenham assegurados seus direitos de aprendizagem e desenvolvimento, em conformidade com o que preceitua o PNE (BRASIL, 2017). 
PES no 06/2018 (Brasil, 2018a). Diante disso, são necessárias mais pesquisas que problematizem os programas de governo impostos sem expressivo diálogo com as entidades da área de educação e as universidades. Nessa ótica, propomos problematizar o modo como se operam o PRP e seus efeitos para a formação de professores.

Na próxima seção, mobilizaremos algumas ferramentas conceituais propostas por Michel Foucault, para problematizar e ampliar as discussões sobre o objeto de estudo. Vamos perspectivar a residência pedagógica como um dispositivo formativo, razão pela qual nos deteremos sobre esse conceito, a seguir. Após isso, vamos reapresentar o objetivo do estudo em termos teóricos.

\section{ONDE HÁ PODER, HÁ RESISTÊNCIA!}

Para Foucault (2018, p. 364), o dispositivo é "um conjunto heterogêneo que engloba discursos, instituições, organizações arquitetônicas, decisões regulamentares, leis, medidas, enunciados científicos, proposições filosóficas, morais, filantrópicas". Segundo Veiga-Neto (2015), o dispositivo é uma rede que interliga todos esses elementos, mantém certas práticas e correlatas instituições articuladas entre si e cuja racionalidade desempenha funções estratégicas. Podemos tomar como exemplo as prisões do século XVIII. Elas foram pensadas e construídas para responder a uma urgência. Segundo Foucault (2018), a arquitetura das celas, em forma de panóptico ${ }^{2}$, imprimia a ideia de vigilância constante, de classificação, de interdição, de separação.

Além disso, podemos argumentar que o dispositivo se caracteriza pelo seu dinamismo, pela capacidade de ação para atingir seus objetivos. Para Foucault (2018), isso é possível porque o dispositivo se constitui em relações de forças que atuam de maneira a direcioná-lo para tal. Tomamos como exemplo o dispositivo jurídico, que desenvolve técnicas e práticas discursivas e não discursivas para chegar a um veredicto e definir quem vai ser vítima ou réu. Essas relações, por sua vez, estão sempre inscritas em um jogo dinâmico de poder que pressupõe um saber que o orienta e que por ele é configurado: "É isto o dispositivo: estratégias de relações de força sustentando tipos de saber e sendo sustentadas por eles" (Foucault, 2018, p. 110). Para o autor, trata-se de um jogo, de uma intervenção constituída nas relações de força, seja para desenvolvê-las em determinada direção, seja para bloqueá-las ou estabilizá-las.

Nesse jogo, o poder mostra-se em ação ao ser exercido e disputado. Segundo Foucault (2017), o poder não é um lugar que se ocupa, nem um objeto que se possui: ele é luta, afrontamento, relação de força, situação estratégica. Entretanto, apesar de excluir, reprimir, censurar e mascarar, o poder também tem eficácia produtiva e riqueza estratégica. É esse aspecto que explica o fato de o poder não se aplicar a um indivíduo ou ser por ele aplicado. O poder atravessa-o, no intuito de dirigir-lhe as

2 O conceito panóptico foi concebido por Jeremy Bentham como um mecanismo aplicável ao controle do comportamento dos prisioneiros nas prisões. O próprio panóptico é uma forma de estrutura arquitetônica projetada para cárceres e prisões. Disponível em: https://www.pensarcontemporaneo.com/teoria-da-panoptica-de-michel-foucault/\#: :text=Embora\%20 a\%20teoria\%20pan\%C3\%B3ptica\%20tenha,projetada\%20para\%20c\%C3\%A1rceres\%20 e\%20pris\%C3\%B5es. Acesso em: 18 mar. 2019. 
condutas, aprimorá-lo, adestrá-lo ou transformá-lo, afirma Foucault (2017). Podemos tomar como exemplo o que ocorre no dispositivo escolar, quando princípios são instituídos para regular a vida dos estudantes. Esses princípios imprimem forte relação de poder e, por conseguinte, de resistência. Para Foucault (2018), onde há poder, há resistência. Não existe propriamente o lugar da resistência, mas pontos móveis e transitórios. De acordo com Castro (2016), para Foucault, a possibilidade de resistência é da ordem estratégica e de luta.

Baseada na ideia de dispositivo como estratégia, Fisher (2002) fala de dispositivo pedagógico. A autora toma como objeto a mídia (e, particularmente, a televisão) e mostra que o dispositivo opera no atravessamento dos sujeitos e suas subjetividades na sociedade contemporânea, na medida em que produz imagens, significações e saberes que se dirigem à "educação" das pessoas, ensinando-lhes modos de ser e estar na cultura. Logo, o dispositivo pedagógico pode ser entendido como um conjunto heterogêneo (de elementos discursivos e não discursivos) que atua no sentido de alcançar uma orientação educacional.

Considerando esse conceito, podemos enunciar que um dispositivo formativo é um tipo de dispositivo pedagógico que se estrutura em torno de um sistema de regras e dirige modos de ser e fazer do professor. $\mathrm{O}$ adjetivo formativo, aqui, faz alusão à formação de professores. Com efeito, então falamos em dispositivo formativo da residência pedagógica (DFRP), para se referir àquele que orienta e dirige a formação inicial de professores por meio da residência pedagógica.

Inspirados em Foucault, entendemos o DFRP como uma rede que institui práticas, ao definir normas e leis, ao propor a organização do espaço e a distribuição do tempo, ao orientar decisões pedagógicas e administrativas que afetam cursos de licenciatura, no espaço institucional da educação superior, articuladas com a educação básica. No caso brasileiro, esse dispositivo teve expansão considerável, provocada pelo PRP, que foi instituído pela CAPES (Portaria no 38/2018), o que acaba por reforçar modos de sujeição e, por consequência, formas de resistência.

Pesquisas apontam que uma primeira experiência de residência pedagógica foi realizada pelo curso de licenciatura em Pedagogia da Universidade Federal de São Paulo (UNIFESP) - campus de Guarulhos -, contemplando um mês de imersão em modalidades como educação infantil, ensino fundamental, educação de jovens e adultos e gestão escolar (Moretti, 2011; Silvestre e Valente, 2014; Reis e Sartori, 2018; Faria e Diniz-Pereira, 2019). Outras experiências foram sinalizadas nessas pesquisas, a exemplo do Colégio Visconde de Porto Seguro (SP), cujo projeto tomou como referência o modelo alemão Referendariat ${ }^{3}$ (ofertado pelo governo; aberto a estudantes no último ano; quatro meses de imersão), do Colégio Pedro

3 Após concluir a universidade, o estudante passa por um estágio probatório. Esse estágio é conhecido como Referendariat, no qual o novo professor acompanha as aulas de outros professores, ensina com a companhia de um veterano e, no fim, dá aulas sozinho em escolas designadas. Essa fase dura entre um e dois anos e só é concluída quando o professor passa por um segundo exame organizado pelo Estado (o primeiro exame é realizado ao final do curso universitário). Disponível em: https://revistaeducacao.com.br/2016/08/08/como-funciona-o-bem-sucedido-ensino-tecnico-da-alemanha/. Acesso em: 1º jun. 2019. 
II (RJ) e do Projeto Residência Docente do Centro Pedagógico da Universidade Federal de Minas Gerais (CP/UFMG), com pós-graduação lato sensu (imersão de nove meses). Essas experiências foram marcadas por orientações que conduziram o processo de formação e que regularam a vida dos envolvidos durante o período em que esteve em vigência. Além disso, observamos que há dispersão semântica em relação à compreensão do termo residência pedagógica para caracterizar as experiências formativas.

Podemos dizer que o DFRP é uma rede marcada por certa racionalidade sobre como devem ser as formações e envolve instituições e discursos que conflitam. Para Foucault (2017), discurso é um conjunto de práticas que designam as coisas $^{4}$ de que se falam e que as instituem. Com efeito, estudar as práticas significa analisar as direções e racionalidades que acompanham os modos de fazer. Porém, embora o dispositivo esteja em plena operacionalização, isso não ocorre sem lutas nem conflitos. Compreendemos conflito como o afrontamento entre linhas de força que carregam diferentes orientações. Segundo Foucault (2018), são essas linhas que fixam os jogos de poder e as configurações de saber que nascem do dispositivo, mas elas também os condicionam.

Diante disso, tomando como referência os estudos de Foucault, argumentaremos que, no DFRP, as relações de força se atritam, para direcionar e para resistir. Assim sendo, agora temos condições de reapresentar um objetivo do estudo aqui relatado: analisar como a implementação do programa fortalece linhas de força no DFRP. A importância deste estudo envolve produzir reflexões críticas sobre esse programa de escala nacional e, por conseguinte, gerar insights a respeito de formas de operar nesse dispositivo.

\section{CONTEXTO}

O PRP faz parte da Política Nacional de Formação de Professores, implementada pela CAPES. O programa, lançado pelo governo, fundamentado nas Portarias da CAPES no 35 e no 45/2018 e no Edital/CAPES no 06/2018, foi instituído em 2018 pela Portaria CAPES no 38/2018, por meio da Diretoria de Formação de Professores da Educação Básica (DEB) da agência, que selecionou instituições de ensino superior para implementar projetos institucionais de residência pedagógica.

O programa integra uma rede de 242 instituições de ensino superior que atuam como polos 5 . Segundo o Edital CAPES no 06/2018 (Brasil, 2018a), a proposta visa apoiar instituições de ensino superior na implementação de projetos inovadores que estimulem a articulação entre teoria e prática nos cursos de licen-

4 Para Foucault (2014), essas “coisas” são os homens em suas relações: as riquezas, os recursos, os meios de subsistência, os costumes, os hábitos, as formas de agir ou de pensar, as desgraças, como a fome, a epidemia, a morte etc.

5 Conforme resultado da terceira etapa da seleção de instituições de ensino superior para participar do Programa Residência Pedagógica. Disponível em: https://www. gov.br/capes/pt-br/centrais-de-conteudo/01082018-resultado-0744166-resultado-terceira-etapa-pagina-da-capes-pdf/view. Acesso em: 30 ago. 2018. 
ciatura, conduzidos em parceria com as redes públicas de educação básica. O Edital CAPES $n^{\circ}$ 06/2018 do PRP indica que foi disponibilizado $\mathrm{R} \$ 1$ bilhão para atender a 45 mil bolsas, que incluem o residente (licenciando), o preceptor (professor/a da educação básica), o orientador e o coordenador institucional (professores/as da instituição de ensino superior).

Segundo o Edital CAPES no 06/2018 (Brasil,2018a), o discente regularmente matriculado em curso de licenciatura deve realizar e desenvolver atividades numa escola pública de educação básica, denominada de escola-campo. O PRP sugere "induzir a reformulação do estágio supervisionado nos cursos de licenciatura, tendo por base a experiência da residência pedagógica" (Brasil, 2018a), bem como "promover a adequação dos currículos e propostas pedagógicas dos cursos de formação inicial de professores da educação básica às orientações da BNCC"(Brasil, 2018a). Diante disso, na próxima seção, vamos apresentar algumas afinidades e afinações relacionadas ao método adotado para a realização desta investigação.

\section{MÉTODO}

Nesta seção, vamos expor as razões de nossas escolhas ao delinear o método de pesquisa, bem como os caminhos trilhados que nos fizeram investigar o alcance do DFRP, após a implementação do programa. Para isso, empreendemos uma análise de como sua implementação fortalece linhas de força no dispositivo.

Nesta investigação, tomamos a ideia de DFRP não apenas para descrevê-lo, mas, em consonância com os argumentos foucaultianos, como a multiplicidade de correlações de forças imanentes ao domínio em que se exercem e constitutivas de sua organização (Foucault, 2018). Para tanto, desenvolvemos uma pesquisa documental. Selecionamos portarias, editais (incluindo os retificados) e os manifestos de entidades ${ }^{6}$ que tinham como foco a residência pedagógica, o que compôs nosso corpus de análise. Tal opção metodológica não implicou negligenciar os comunicados que sinalizaram possibilidades de adesão ao programa, a exemplo das notas da Associação Nacional pela Formação dos Profissionais da Educação (ANFOPE), publicadas em 2 de abril de 2018, e do Sindicato Nacional dos Docentes das Instituições de Ensino Superior (ANDES), de 5 de abril de 2018.

Os dados foram organizados em um quadro analítico, nos quais foram acrescidos observações e comentários, tomando como referência o objetivo delineado

6 Associação Nacional de Pós-Graduação e Pesquisa em Educação (ANPEd), Associação Nacional pela Formação dos Profissionais da Educação (ANFOPE), Confederação Nacional dos Trabalhadores em Educação (CNTE), Fórum Nacional de Diretores de Faculdades, Centros de Educação ou Equivalentes das Universidades Públicas Brasileiras (FORUMDIR), Associação Nacional de Política e Administração da Educação (ANPAE), Associação Brasileira de Currículo (ABdC), Centro de Estudos Educação e Sociedade (CEDES), Associação Nacional de Pesquisa em Financiamento da Educação (FINEDUCA), Campanha Nacional pelo Direito à Educação, Ação Educativa, Movimento Nacional em Defesa do Ensino Médio (MNDEM) e Rede Escola Pública e Universidade (REPU). 
para esta investigação. Com base no que propõe Paraíso (2012), no processo de análise do DFRP, verificamos o funcionamento das relações de poder travadas, as estratégias utilizadas e os discursos que foram legitimados ou excluídos, a fim de que pudessem ser autorizados e divulgados.

Após análise preliminar, estabelecemos relações entre os documentos selecionados e apontamos e fixamos os pontos de ancoragem. Por fim, argumentamos que esses documentos selecionados nos deram indícios sobre quais linhas de força do DFRP são corroboradas com a implementação do programa e, portanto, configuram determinadas resistências.

\section{O QUE ESTÁ EM JOGO}

Nesta seção, socializaremos uma problematização que foi empreendida tomando como referência os documentos analisados. Na sequência, apresentaremos cinco pontos de ancoragem: o duelo entre teoria e prática, a reformulação do estágio, a relação universidade e escola, a associação do PRP à BNCC e a autonomia das instituições formadoras. Esses pontos emergiram dos dados e foram sistematizados por meio de um diálogo com alguns conceitos foucaultianos.

\section{O DUELO ENTRE TEORIA E PRÁTICA}

Parece-nos provocador iniciarmos esta subseção tecendo considerações a respeito do significado da palavra duelo. No sentido figurado, poderíamos tomar duelo como a oposição conflituosa de ideias, forças, pessoas etc. (Ferreira, 2010). Essa perspectiva legitima a forma de operação de um dispositivo, visto que opera por mecanismo de sujeição e de resistência, portanto, por conflitos, nos termos postos por Foucault (2018).

Tomaremos essa ideia para argumentar que, há décadas, a literatura tem evidenciado um duelo entre os papéis da teoria e da prática na formação de professores (Pimenta, 2012; Veiga-Neto, 2015). Veiga-Neto (2015) afirma que, apesar das diferentes vertentes epistemológicas que colocam em xeque os termos teoria e prática, todas elas são unânimes em afirmar que uma depende da outra.

Entretanto, no âmbito do PRP, a proposta apresentada não deixa claro como a teoria vai subsidiar a prática nem vice-versa, como podemos ver no primeiro objetivo do Edital no 06/2018:

Aperfeiçoar a formação dos discentes de cursos de licenciatura, por meio do desenvolvimento de projetos que fortaleçam o campo da prática e conduzam o licenciando a exercitar de forma ativa a relação entre teoria e prática profissional docente, utilizando coleta de dados e diagnósticos sobre o ensino e a aprendizagem escolar, entre outras didáticas e metodologias. (Brasil, 2018a)

No objetivo apontado, a racionalidade posta em operação parece perpassar por um caráter pragmático da prática pedagógica. $\mathrm{O}$ caminho apresentado sugere modos de fazer, ao sinalizar o desenvolvimento de projetos, e de agir dos sujeitos, a exemplo dos discentes (denominados de residentes no PRP), ao sugerir que 
"o licenciando exercite de forma ativa a relação teoria e prática” (Brasil, 2018a). Observa-se que, mesmo propondo uma suposta articulação, há ênfase nas ações possíveis a serem desenvolvidas nas escolas-campo. Ou seja, é dada importância à dimensão prática, mas sem clarear como ela se articula com a teoria.

As entidades da sociedade civil posicionaram-se contrariamente ao direcionamento dado pelo Edital CAPES no 06/2018. Elas argumentam que esse ponto constitui uma visão reducionista e conduz a formação docente à realização de ações desvinculadas de questões teóricas, como sinalizado no trecho do manifesto a seguir: "Incorre em uma visão reducionista da formação de professores uma vez que reduz 'a formação docente a um 'como fazer' descompromissado de uma concepção sócio histórico e emancipadora”' (ANPEd, 2017).

Observamos que, no trecho em destaque, as entidades operam com uma tática de resistência ao proferir o discurso de acusação de que há um retrocesso em relação à compreensão do processo de formação de professores. As linhas de resistência colocam em funcionamento uma leitura do Edital CAPES no 06/2018 em termos de redução à prática e de uma possível ruptura entre os "saberes práticos" e os "saberes tácitos”, conforme conceitos apresentados por Monteiro (2003) e Tardif (2006). Parece, portanto, dizer que, por um lado, temos uma ênfase pragmática na relação teoria e prática e, por outro lado, acusação de supervalorização dos saberes práticos.

\section{A REFORMULAÇÃO DO ESTÁGIO}

Desde a Resolução CNE/CP no 2/2002 até os dias atuais, a legislação tem estipulado 400 horas de estágio curricular supervisionado a partir do início da segunda metade do curso (Brasil, 2002; 2015). A expectativa era que o aumento da carga horária para esse componente favorecesse a aproximação dos licenciandos com o ambiente escolar de forma mais sistemática e intensa, entretanto pesquisas têm argumentado que o desenho proposto para a realização dos estágios não tem contribuído para uma formação sólida (Teixeira e Cyrino, 2015; Pimenta e Lima, 2017). Para Pimenta e Lima (2017), o que se observa é uma falta de articulação entre universidade e escola, gerando equívocos na formação docente.

Pesquisas têm defendido a realização de atividades de estágio em duas perspectivas: como campo de pesquisa e como colaboração (Medeiros, 2010; Gonçalves Júnior, 2009; Lima 2009). Lima (2009) argumenta que o estágio enquanto pesquisa pode conduzir aos estudos e à concretização das ideias, transformando-as em atividades, posturas metodológicas e ações pedagógicas ligadas ao ensinar e ao aprender, enfatizando a sua importância para a formação acadêmica e para a constituição da identidade profissional ${ }^{7}$. Por sua vez, Medeiros (2010) e Gonçalves Júnior (2009) apresentam a ideia de estágio como colaboração na perspectiva de que professores, orientadores e estudantes trabalharem em conjunto de modo a atingir um objetivo comum em prol do ensino e da aprendizagem.

7 De acordo com Hall (2015, p. 11-12), “a identidade profissional é formada e transformada continuamente em relação às formas pelas quais somos representados ou interpelados nos sistemas culturais que nos rodeiam”. 
Partiremos do pressuposto de que o estágio consiste no momento de inserção do licenciando no campo de atuação, tomando-o em objeto de pesquisa, estudo, análise e interpretação crítica, fundamentando-se nas componentes curriculares do curso (Teixeira e Cyrino, 2015; Pimenta e Lima, 2017). Como parte de um dispositivo formativo, o estágio ganha materialidade em torno de uma série de legislações que conduzem a obrigatoriedade para todos os cursos de licenciatura, a exemplo do que estabelecem as Diretrizes Curriculares para a Formação de Professores, como apresentado no artigo a seguir: "Art. $13 \S 6^{\circ} \mathrm{O}$ estágio curricular supervisionado é componente obrigatório da organização curricular das licenciaturas, sendo uma atividade específica intrinsecamente, articulada com a prática e com as demais atividades de trabalho acadêmico" (Brasil, 2015, p. 11).

O trecho supracitado estabelece a possibilidade de que aquilo tido como modelo de estágio seja historicamente ampliado e articulado com as demais atividades acadêmicas. O que significa dizer que deparamos com a necessidade de superação de dicotomias ainda presentes, como, por exemplo: teoria e prática, e universidade e escola (Pimenta, 2012; Khaoule e Carvalho, 2014).

Segundo Khaoule e Carvalho (2014), tal desafio convida-nos a entender o processo de formação profissional não mais baseado na racionalidade técnica nem/ou na prática modelar, mas por meio de reflexões do cotidiano escolar, tomando como base a articulação entre teoria e prática. O PRP, porém, estabelece como objetivo "induzir a reformulação do estágio supervisionado nos cursos de licenciatura, tendo por base a experiência da residência pedagógica" (Brasil, 2018a).

Considerando o objetivo preconizado pelo PRP, podemos argumentar que as direções e racionalidades apontadas sugerem uma reformulação das propostas de estágio já existentes nos projetos pedagógicos dos cursos de licenciatura em todo o país, entretanto inferimos que as orientações sugeridas no Edital CAPES no 06/2018 não garantem uma possível reformulação do estágio. Outros elementos constitutivos da formação docente precisam ser levados em conta, não silenciados nem inibidos na proposta apresentada. Segundo o posicionamento da ANPEd (2018), o que se propõe é um formato conservador e tradicional, limitando-se as atividades de estágio à hora da prática.

Além disso, o PRP prevê o parcelamento de horas de ambientação, imersão e regência, de forma pontual, nas escolas-campo. A proposta legitima o caráter horista em que os estudantes, denominados de residentes, precisam cumprir 440 horas de atividades sob a supervisão do professor da educação básica (preceptor), conforme o trecho a seguir:

A residência pedagógica terá o total de 440 horas de atividades distribuídas da seguinte forma: 60 horas destinadas à ambientação na escola; 320 horas de imersão, sendo 100 de regência, que incluirá o planejamento e execução de pelo menos uma intervenção pedagógica; e 60 horas destinadas à elaboração de relatório final, avaliação e socialização de atividades. (Brasil, 2018a)

$\mathrm{O}$ trecho sugere uma lógica unificada em âmbito nacional em que os licenciandos devem desenvolver atividades previamente definidas pelo próprio 
programa. Segundo Silva e Cruz (2018), o problema não se restringe à distribuição da carga horária para o desenvolvimento das atividades, mas há um interesse explícito do PRP em induzir a forma e o conteúdo das atividades e reflexões sobre o trabalho docente que atravessam ações de estágio. Segundo as autoras, outra questão que deve ser problematizada é a ênfase nas atividades práticas, entendidas como imersão na sala de aula, centrando o ato pedagógico no fazer metodológico-curricular. Essa lógica consolida uma relação hierárquica e excludente entre teoria e prática e universidade e escola, como já sinalizado pelas entidades:

Nesses termos, entende-se que o Edital no 06/2018 desconsidera o amplo debate do campo da formação de professores, a Resolução CNE/CP no 2/2015, a importância e riqueza das diversas experiências em andamento no Brasil em diferentes universidades e cursos, retomando a velha fórmula observação, participação e regência, desta feita consorciada a oferta de bolsas para estudantes e professores no contexto dos estágios obrigatórios, autodenominada de residência pedagógica. (ANPEd, 2017)

A perspectiva defendida é de que as propostas a serem submetidas precisam enfatizar e fortalecer o projeto institucional de formação via implementação das Diretrizes Curriculares Nacionais para a Formação de Professores (Resolução CNE 02/2015), assim como a concepção de trabalho docente, formação e teoria e prática que as informa, rejeitando, portanto, o pragmatismo e o aligeiramento da formação. (ANFOPE, 2018)

Observa-se nesses trechos que as entidades colocam em cena uma história de luta travada durante anos em que pleiteavam transformações relacionadas à forma de interação entre universidade e escola e ao incentivo à valorização profissional, por meio de programas delineados em parceria com as instituições de ensino superior. Nota-se que, por um lado, o programa coloca em ênfase como os estágios devem ocorrer, limitando-se apenas às experiências vivenciadas no PRP e articuladas à observação, participação e regência. Por outro lado, no discurso proferido pelas entidades, as formas de resistência estão vinculadas à rejeição e restrição à continuidade da tríade observação, participação e regência, que, por vezes, desconsideram as concepções de estágio enquanto campo de pesquisa e colaboração, como discutido por Pimenta e Lima (2017).

\section{A RELAÇÃO UNIVERSIDADE E ESCOLA}

$\mathrm{Na}$ área da educação, diferentes discursos têm circulado no intuito de criar possibilidades de articulação entre universidade e escola (Zeichner, 2010; Pimenta e Lima 2017). Em geral, esses discursos apoiam-se em enunciados já proferidos de que há uma crise do trabalho docente. Segundo Fiorentini (2009) e Zeichner (2010), essa crise tem afetado também os centros de formação inicial de professores. Diante disso, para os autores, uma forma de superar essa crise é a elaboração de projetos de cursos que proponham um currículo com conteúdos e atividades de estágios articulados com a realidade escolar. 
Por sua vez, o PRP enuncia como alguns de seus objetivos: "Fortalecer, ampliar e consolidar a relação entre a [instituição de ensino superior] IES e a escola, promovendo sinergia entre a entidade que forma e a que recebe o egresso da licenciatura e estimulando o protagonismo das redes de ensino na formação de professores" (Brasil, 2018a).

Observa-se que os objetivos propostos preveem aproximação entre universidade e escola, entretanto esse discurso coloca em funcionamento um estilo em que cada instituição se torna responsável por uma ação: universidade forma e escola acolhe o estudante - "a relação entre a IES e a escola, promovendo sinergia entre a entidade que forma e a que recebe o egresso da licenciatura" (Brasil, 2018a).

Além disso, o Edital CAPES no 06/2018 recomenda que na construção do projeto institucional as "expectativas e sugestões dos dirigentes das escolas e da rede de ensino ao qual pertencem as escolas" (Brasil, 2018a) devam ser contempladas pelos projetos/subprojetos. Essa proposição limita a possibilidade de trabalhos em parceria ao conduzir o diálogo que tem de ser proferido. Parece-nos que temos duas linhas conflituosas. A primeira é a separação entre entidade formadora e entidade receptora; e a outra, a ideia de que a universidade pode - aparentemente sozinha - lidar com as expectativas das escolas e das redes, em vez de um trabalho conjunto, compartilhado.

Por conseguinte, o modelo proposto no Edital CAPES no 06/2018 provocou algumas inquietações por parte das entidades, como podemos observar no trecho adiante:

O discurso de MEC/CAPES que celebra a sinergia entre escola e universidade encobre o fato de que o Programa de Residência Pedagógica é uma tentativa de desconstrução de projetos de formação inicial comprometidos com a docência como atividade intelectual e criadora. Isso tem efeitos profundamente desprofissionalizantes nos cursos de Licenciatura. (ANPEd, 2017)

Por um lado, o modo como o programa se apresenta propõe um regime de colaboração que poderia possibilitar ao licenciando vivenciar experiências em outro locus de formação que não a universidade, como posto por Grigoli et al. (2010) e Santana e Barbosa (2019a, 2019b), ao mesmo tempo em que poderia demarcar a aproximação entre universidade e escola. Por outro lado, no discurso proferido pelas entidades, as formas de resistência estão vinculadas à desarticulação e desconstrução de projetos já existentes para a formação inicial, podendo colocar em xeque a qualidade profissional do futuro professor.

\section{A ASSOCIAÇÃO DO PROGRAMA RESIDÊNCIA PEDAGÓGICA À BASE NACIONAL COMUM CURRICULAR}

Esta subseção parte do pressuposto de que a BNCC se configura como um "documento de caráter normativo que define o conjunto orgânico e progressivo de aprendizagens essenciais que todos os alunos devem desenvolver ao longo das etapas e modalidades da Educação Básica” (Brasil, 2017, p. 5). Segundo Macedo (2014), a BNCC foi inspirada na experiência americana do núcleo comum (common core), 
conjunto de indicadores para avaliação marcado pela forma de gestão preconizada pelos agentes políticos privados participantes da rede, a exemplo da Fundação Bill e Melinda Gates e da Pearson Corporation. Para a autora, o que está em curso é uma arquitetura de regulação e controle do que será ensinado e aprendido, cujas conjeturas se valem de articulações hegemônicas para constituir sujeitos.

No âmbito do PRP, podemos notar que, ao tomar as orientações da BNCC como um dos eixos para o desenvolvimento da proposta, se observa um ideário da disciplina, do controle do tempo, do controle do espaço, do controle das ações. Para exemplificarmos, analisamos o seguinte objetivo: "Promover a adequação dos currículos e propostas pedagógicas dos cursos de formação inicial de professores da educação básica às orientações da BNCC” (Brasil, 2018a).

A CAPES, ao propor a associação do PRP à BNCC, legitima uma corporificação no currículo tanto para a educação básica quanto para os cursos de formação de professores. Essa estratégia de associação foi repudiada por diferentes entidades, como verificamos nos trechos a seguir: "Repudiamos qualquer associação desses Programas [PIBID e PRP] à BNCC, caracterizada pelo estreitamento curricular e cujo processo de elaboração, discussão e aprovação tem sido alvo de críticas contundentes das entidades acadêmicas e científicas desde 2015" (ANPEd, 2017).

A concepção do PRP indica a vinculação entre o currículo dos Cursos de Licenciatura e a Base Nacional Comum Curricular (BNCC), o que precisa ser visto com muita cautela, pois isso estabelece uma relação direta e linear do projeto político pedagógico elaborado pelos cursos de formação docente nas Instituições de Ensino Superior, com os exames em larga escala e externos que norteiam os currículos das escolas, com apoio do PNE. (ANDES, 2018)

Observamos que os trechos selecionados conflitam com o que foi apresentado pelo PRP. Afinal, temos a proposta de associar o programa à $\mathrm{BNCC}$ e aos projetos pedagógicos de formação das universidades, sem levar em consideração as diretrizes existentes no Brasil. Nessa teia, como uma forma de afrontamento, as entidades manifestaram-se contrárias, porque a proposta afeta diretamente a autonomia das universidades e dos colegiados ao sugerir um redirecionamento dos projetos pedagógicos dos cursos de licenciatura. Podemos inferir que a linha de resistência se acentua, porque a proposta visa ampliar e diversificar a área de abrangência para que se possa incrementar o número maior de sujeitos que se identifiquem e propaguem os preceitos apresentados na BNCC.

\section{AUTONOMIA DAS INSTITUIÇÕES FORMADORAS}

A questão da autonomia das universidades constitui uma âncora central e foi ponto de pauta nas quatro âncoras anteriores, citadas neste artigo. A temática é amplamente discutida e defendida pela comunidade acadêmica e toma como pressuposto o que estabelece o artigo 207 da Constituição Federal: "As universidades gozam de autonomia didático-científica, administrativa e de gestão financeira e patrimonial, e obedecerão ao princípio de indissociabilidade entre ensino, pesquisa e extensão" (Brasil, 1988). 
Para Dourado (2011), o artigo da Constituição garante a autonomia das universidades, mas a implementação do dispositivo constitucional esbarra em limites de toda ordem, conferindo às universidades diferentes estágios na efetivação desse direito constitucional. Para o autor, para melhor definir o espectro de atuação do texto da Constituição, a Lei de Diretrizes e Bases da Educação (LDB) reforça e regulamenta a gratuidade no ensino público em todos os níveis, a gestão democrática da escola pública, a indissociabilidade entre ensino, pesquisa e extensão na educação universitária, a autonomia das universidades, entre outros e foi precedida por edição de leis, decretos e portarias que a nortearam (Brasil, 1996).

Entretanto, a autonomia da universidade como instituição responsável pela formação inicial de professores de nível superior voltou a ser problematizada após o lançamento do Edital CAPES no 06/2018, como sinalizado pelas entidades no trecho:

Consideramos inadequado que os dois Editais [PIBID e Programa de Residência Pedagógica] estipulem como critérios a vinculação das propostas à $\mathrm{BNCC}$, pois isto fere a autonomia universitária e conflitua com os projetos institucionais das IES, debatidos e aprovados nas instâncias colegiadas das instituições formadoras, e mais, está em total desacordo com as orientações da Resolução CNE 02/2015 que estabelece as Diretrizes Curriculares Nacionais para a Formação Inicial e Continuada de Professores no Brasil. (ANFOPE, 2018)

O que temos é uma proposta, considerada no próprio Edital CAPES n ${ }^{\circ}$ 06/2018 como uma experiência piloto, que opera por meio da padronização da formação. De maneira oposta, observamos no trecho em destaque que as entidades operam com uma tática de resistência à regulamentação prevista pelo referido edital. As linhas de resistência colocam em funcionamento uma leitura do Edital CAPES no 06/2018, acusando-o de negligenciar documentos legais, como, por exemplo, as Diretrizes Curriculares Nacionais para a Formação Inicial e Continuada de Professores no Brasil, que orientam os projetos político-pedagógicos dos cursos de licenciatura. Além disso, há ainda outra preocupação de ordem estrutural:

O PRP, pela sua configuração, pode incentivar as IES e as escolas-campo a utilizarem o(a)s bolsista-residentes a substituírem o(a)s professore(a)s nos seus impedimentos, mascarando a falta numérica de docentes nas escolas e utilizando o(a)s bolsistas a assumirem funções para as quais não estão ainda preparado(a)s. (ANDES, 2018)

Há, portanto, especulações de que os bolsistas possam substituir professores nas escolas-campo. Constatamos que a retórica construída pelo Sindicato Nacional dos Docentes das Instituições de Ensino Superior (ANDES) sinaliza um possível risco, mas a atenção deve voltar-se para as ações articuladas entre universidade e escola e para as funções que os residentes devem desenvolver. As entidades argumentam que a desprofissionalização da carreira constitui uma estratégia que também fere a autonomia universitária. 


\section{DISCUSSÃO}

$\mathrm{Na}$ seção anterior, apresentamos cinco pontos de ancoragem que ilustraram o afrontamento entre linhas de força que carregam diferentes orientações. A nossa intenção foi analisar como a implementação do PRP fortalece determinadas linhas de força no DFRP. Para isso, partimos do pressuposto de que o dispositivo, que tinha uma ação limitada, a exemplo da UNIFESP (Moretti, 2011), ganha visibilidade com a implementação de um programa em dimensão nacional. O programa coloca em relevo linhas de força, sentidos, direções, mas ao mesmo tempo todos esses elementos são desafiados.

Ao analisar a trama, mostramos que o programa opera com normas de padronização de condutas, que determinam tanto a formação como a atuação, ao passo que as entidades resistem e desafiam a proposta imposta para a formação de professores. Para desafiar as linhas de força corroboradas pelo programa, as entidades utilizam a estratégia da acusação de que há um retrocesso.

Observamos que o Edital CAPES no 06/2018 não sinaliza claramente como se darão as relações entre teoria e prática, entre $\mathrm{PRP}$ e $\mathrm{BNCC}$ e entre o programa e o componente de estágio que compõe a grade curricular dos cursos de licenciatura. Enquanto o programa desconsidera a legislação e as pesquisas que tematizam a formação de professores, as entidades, como um modo de resistência, rejeitam e repudiam o formato delineado pelo programa, visto que a homogeneização da proposta não contempla as particularidades de cada curso. Além disso, para Cosenza (2018) e Silva e Cruz (2018), a estrutura sugerida induz as instituições de ensino superior a reorganizarem seus projetos de curso às características do edital.

Inscreve-se nesse debate a obrigatoriedade de associação do programa à BNCC. Nesse cenário, agrupam-se instituições, sujeitos e interesses diversos com o propósito de propagar um documento que unificará os currículos tanto da educação básica quanto da formação inicial de professores. Em oposição, as entidades repudiam qualquer tentativa de vinculação dos programas de formação inicial das instituições de ensino superior à $\mathrm{BNCC}$, por ferir a autonomia das universidades. Segundo Cosenza (2018), uma possível associação do PRP à BNCC destoa das concepções de formação docente presentes nos seus próprios projetos pedagógicos, violando o preconizado pelo PNE e pela Resolução CNE/CP no 2/2015, que definem as Diretrizes Curriculares Nacionais para a Formação Inicial e Continuada de Professores no Brasil. Inspirados em Foucault (2018), poderíamos dizer que a luta é contra a sujeição e a submissão.

Como oposição a essa forma de sujeição, a ANFOPE (2018) sugeriu que as instituições de ensino superior elaborassem projetos institucionais que subvertessem as normas postas pelo edital. Por fim, a associação demarca que "a adesão aos Editais [PIBID e PRP] é uma forma de resistência propositiva e não de submissão" (ANFOPE, 2018).

Nessa perspectiva, para que o DFRP ganhe materialidade, precisamos não só subverter o programa de iniciação à docência, mas propor um novo design para ele de forma a contemplar uma real articulação entre os diferentes componentes dos cursos de licenciatura, os estágios e a educação básica. Necessitamos diminuir o 
excesso de burocratização (preenchimento de formulários e relatórios) e investir em pesquisa nos diferentes contextos de formação inicial e continuada, considerando aspectos relacionados à interdisciplinaridade e à diversidade sociocultural em que os sujeitos estão inseridos.

\section{CONSIDERAÇÕES FINAIS}

A residência pedagógica, como uma oportunidade de iniciação à docência, constitui uma atividade de formação feita por um discente regularmente matriculado em curso de licenciatura e desenvolvida numa escola pública de educação básica, denominada de escola-campo. Durante o período de participação no programa, o estudante é acompanhado por um professor da educação básica (preceptor), que leciona na escola-campo, e é orientado por um docente da instituição de ensino superior. A coordenação do Projeto Institucional de Residência Pedagógica é realizada por um docente da instituição de ensino superior, chamado de coordenador institucional. Ao propor analisar como a implementação desse programa corrobora linhas de força no DFRP, enfatizamos o papel das resistências como constitutivas desse dispositivo.

Os resultados indicam que as manifestações de resistência foram decorrentes dos questionamentos à política pública para a formação de professores preconizada pelo Edital CAPES no 06/2018. Nesta investigação, identificamos que os modos de resistência operacionalizados atravessaram o dispositivo colocando em relevo quatro estratégias: acusação, rejeição, restrição e repúdio. Essas estratégias, por sua vez, podem perpassar por dois tipos de resistência: as resistências híbridas, que se opõem à mistura de dois ou mais elementos do dispositivo, a exemplo da vinculação do estágio e da PRP; e as resistências flutuantes, que oscilam em oposição a questionamentos envolvendo aspectos políticos e sociais relacionados à formação de professores, a exemplo da autonomia das universidades para a elaboração dos projetos dos cursos. Mas faz-se importante destacar que, em alguns momentos, é possível apontar sobreposições.

Essa análise microssocial sugere uma reestruturação da proposta e sinaliza que as entidades requerem que o programa dialogue com os projetos pedagógicos de formação das universidades e com a legislação vigente sobre formação de professores, a fim de diminuir a lacuna existente. Estamos tomando o conceito de resistência como uma ação propositiva, como um movimento contra a sujeição. Como posto por Apis (2011), poderíamos falar em re-existência, como um movimento de criação. Uma insistência em estruturar uma proposta de residência pedagógica que atenda às demandas da comunidade.

Por decorrência, a presente investigação aponta para a necessidade de reestruturação do programa, levando em conta um conjunto de diretrizes curriculares existentes no Brasil. Isso não significa que o programa deva se restringir à legislação vigente, mas tomá-la como ponto de partida para a problematização e orientação das condutas, sem desconsiderar as particularidades advindas dos cursos de licenciatura nem da educação básica. Com efeito, a proposta preconizada pelo Edital CAPES 
$n^{\circ}$ 06/2018 poderia ter seu discurso legitimado e autorizado. Desse modo, novas pesquisas sobre essa temática precisam ser agendadas.

\section{AGRADECIMENTOS}

Ainda que não sejam responsáveis pelas posições adotadas neste artigo, nossos agradecimentos à professora doutora Fernanda Wanderer, da Universidade do Vale do Rio dos Sinos (UNISINOS), e aos membros do Grupo de Ensino de Ciências e Matemática (ENCIMA), as contribuições. Ao Professor Ms. Guttemberg Magalhães Oldack Barbosa, as contribuições no processo de revisão deste artigo. Aos professores da educação básica Roseneide dos Santos Alves (Colégio Estadual General Osório), Daniel Borges de Oliveira (Colégio Estadual Padre Vieira) e Cristiane Medeiros Queiroz Penna (Colégio Modelo Luís Eduardo Magalhães) e aos estudantes do curso de licenciatura em Matemática da Universidade Estadual de Feira de Santana (UEFS), que nos inspiraram a investigar a residência pedagógica.

\section{REFERÊNCIAS}

APIS, R. L. Um ensino de Filosofia e resistência política e (des)governamentalidade e subversões. Educação em Revista, Marília, v. 12, n. 1, p.169-180, jan./jun. 2011. https:// doi.org/10.36311/2236-5192.2011.v12n1.1546

ASSOCIAÇÃO NACIONAL DE PÓS-GRADUAÇÃO E PESQUISA EM EDUCAÇÃO (ANPED). A política de formação de professores no Brasil de 2018: uma análise dos Editais CAPES de Residência Pedagógica e PIBID e a reafirmação da Resolução CNE/CP 02/2015. Brasil: ANPEd, 2018. Disponível em: https://www. anped.org.br/sites/default/files/images/formacaoprofessores_anped_final.pdf. Acesso em: 2 jun. 2018.

ASSOCIAÇÃO NACIONAL DE PÓS-GRADUAÇÃO E PESQUISA EM EDUCAÇÃ O (ANPED). Manifestação das entidades educacionais sobre a política de formação de professores anunciada pelo MEC. Brasil: ANPEd, 2017. Disponível em: http://www.anped.org.br/news/manifestacao-das-entidades-educacionais-sobrepolitica-de-formacao-de-professores-anunciada. Acesso em: 15 maio 2018.

ASSOCIAÇÃO NACIONAL PELA FORMAÇÃO DOS PROFISSIONAIS DA EDUCAÇÃO (ANFOPE). Resistência propositiva e contra hegemônica: posição da ANFOPE sobre a adesão aos Editais 06/2018 - PIBID. Brasil: ANFOPE, 2018. Disponível em: http://webcache.googleusercontent.com/ search?q=cache:oMwhCuO0ppIJ:www.gppege.org.br/ArquivosUpload/1/file/RESIS T\%25C3\%258ANCIA\%2520PROPOSITIVA\%2520E\%2520CONTRA\%2520HE GEM\%25C3\%2594NICA.docx+\&cd=1\&hl=pt-BR\&ct=clnk\&gl=br. Acesso em: 15 abr. 2018.

BALL, S. J.; MAINARDES, J. (org.). Políticas educacionais: questões e dilemas. São Paulo: Cortez, 2011. 
BARBOSA, M. V.; FERNANDES, N. A.M. (org.). Políticas públicas para a formação de professores. Brasília: Ministério da Educação, 2017.231 p. (Em Aberto, v. 30, n. 98). BERRY, B. et al. Creating and sustaining urban teacher residencies. Hillsborough: Center for Teaching Quality and the Aspen Institute, 2008.

BRASIL. Base Nacional Comum Curricular (BNCC). Educação é a Base. Brasília: MEC/CONSED/UNDIME, 2017. Disponível em: http://basenacionalcomum.mec. gov.br/images/BNCC_EI_EF_110518_versaofinal_site.pdf. Acesso em: 2 jun. 2017.

BRASIL. Constituição da República Federativa do Brasil de 1988. Brasília: Presidência da República, 1988. Disponível em: http://www.planalto.gov.br/ccivil_03/ constituicao/constituicao.htm. Acesso em: 15 jan. 2019.

BRASIL. Lei no 9.394, de 20 de dezembro de 1996. Estabelece as Diretrizes e Bases da Educação Nacional. Diário Oficial da União, Brasília, v. 134, n. 248, Seção 1, p. 27834-27841, 1996.

BRASIL. Ministério da Educação. Coordenação de Aperfeiçoamento de Pessoal de Nível Superior. Edital no 06/2018 CAPES. Programa Residência Pedagógica. Brasília: CAPES, 2018a. 21 p. Disponível em: http://cfp.ufcg.edu.br/portal/images/ conteudo/PROGRAMA_RESIDENCIA_PEDAGOGICA/DOCUMENTOS_E_ PUBLICACOES/01032018-Edital-6-2018-Residencia-pedagogica.pdf. Acesso em: 20 abr. 2018.

BRASIL. Ministério da Educação. Secretaria de Articulação com os Sistemas de Ensino. Planejando a próxima década: conhecendo as 20 metas do Plano Nacional de Educação. Brasília: Ministério da Educação, 2014. Disponível em http://pne.mec.gov. br/images/pdf/pne_conhecendo_20_metas.pdf. Acesso em: 20 jun. 2015.

BRASIL. O Plano de Desenvolvimento da Educação: razões, princípios e programas. Brasília: MEC, 2007.

BRASIL. Portaria no 38, de 28 de fevereiro de 2018. Institui o Programa de Residência Pedagógica. Diário Oficial da União, Brasília, 2018b.

BRASIL. Resolução CNE/CP no 02/2012, de 19 de fevereiro de 2002. Institui a duração e a carga horária dos cursos de licenciatura, de graduação plena, de formação de professores da Educação Básica em nível superior. Diário Oficial da União, Brasília, 19 fev. 2002.

BRASIL. Resolução CNE/CP no 02/2015, de 1º de julho de 2015. Define as Diretrizes Curriculares Nacionais para a formação inicial em nível superior (cursos de licenciatura, cursos de formação pedagógica para graduados e cursos de segunda licenciatura) e para a formação continuada. Diário Oficial da União, Brasília, p. 8-12, 2 jul. 2015.

CASTRO, E. Vocabulário de Foucault: um percurso pelos seus temas, conceitos e autores. 2. ed. Belo Horizonte: Autêntica, 2016.

COSENZA, A. Formação Docente no Pibid: entre a potência e a resistência. Pesquisa e Debate em Educação, São Paulo, v. 8, n. 1, p. 700-707, 2018.

DOURADO,L. F. Políticas e gestão da educação básica no Brasil: limites e perspectivas. Educação e Sociedade, Campinas, v. 28, n. esp. 100, p. 921-946, out. 2007. https://doi. org/10.1590/S0101-73302007000300014 
DOURADO, L. F. Políticas e gestão da educação superior no Brasil: múltiplas regulações e controle. Revista Brasileira de Política e Administração da Educação, Goiás, v. 27, n. 1, p. 53-65, jan./abr. 2011. https://doi.org/10.21573/ vol27n12011.19967

FARIA, J. B.; DINIZ-PEREIRA, J. E. Residência pedagógica: afinal, o que é isso? Revista de Educação Pública, Cuiabá, v. 28, n. 68, p. 333-356, maio/ago. 2019. https:// doi.org/10.29286/rep.v28i68.8393

FERREIRA, A. B. de H. Miniaurélio: o dicionário da língua portuguesa. 8. ed. Curitiba: Positivo, 2010.

FIORENTINI, D. Educação matemática: diálogos entre universidade e escola. In: ENCONTRO GAÚCHO DE EDUCAÇÃO MATEMÁTICA, 10., 2009, Ijuí. Anais... Ijuí: UNIJUÍ/Departamento de Física, Estatística e Matemática, 2009.

FISHER, R. M. B. O dispositivo pedagógico da mídia: modos de educar na (e pela) TV. Educação e Pesquisa, São Paulo, v. 28, n. 1, p. 151-162, jan./jun. 2002. https://doi. org/10.1590/S1517-97022002000100011

FOUCAULT, M. História da sexualidade I: a vontade de saber. 7. ed. Rio de Janeiro: Edições Graal, 2018.

FOUCAULT, M. História da sexualidade III: o cuidado de si. São Paulo: Paz e Terra, 2014.

FOUCAULT, M. Sobre a história da sexualidade. In: MACHADO, R. (org.). Microfísica do poder. Rio de Janeiro: Paz e Terra, 2017.

GONÇALVES JÚNIOR, M. A. Uma pesquisa sobre o estágio na licenciatura em matemática: considerações sobre as possibilidades metodológicas. In: SEMINÁRIO INTERNACIONAL DE PESQUISA EM EDUCAÇÃO MATEMÁTICA, 4., 2009, Brasília. Anais... Brasília: SBEM, 2009.

GRIGOLI, J. A. G. et al. A escola como lócus de formação docente: uma gestão bemsucedida. Cadernos de Pesquisa, São Paulo, v. 40, n. 139, p. 237-256, jan./abr. 2010. http://doi.org/10.1590/S0100-15742010000100012

HALL, S. A identidade cultural na pós-modernidade. 12. ed. Rio de Janeiro: Lamparina, 2015.

KHAOULE, A. M. K.; CARVALHO, E. F. O estágio na formação de formadores: superar o modelo, ultrapassar a técnica, efetivar a reflexão. Revista Brasileira de Educação Geográfica, Campinas, v. 4, n. 7, p. 100-124, jan./jun. 2014.

LIMA, M. S. L. O estágio nos cursos de licenciatura e a metáfora da árvore. Pesquiseduca, Santos, v. 1, n. 1, p. 45-48, jan.-jun. 2009.

MACEDO, E. Base nacional curricular comum: novas formas de sociabilidade produzindo sentidos para educação. Revista e-Curriculum, São Paulo, v. 12, n. 3, p. 1530-1555, out./dez. 2014.

MEDEIROS, C. M. Estágio Supervisionado: uma influência na constituição dos saberes e do professor de matemática na formação inicial. 2010. 138f. Dissertação (Mestrado em Educação) - Instituto de Educação Matemática e Ciências, Universidade Federal do Pará, Belém, 2010. 
MONTEIRO,A.M.C. Entre saberes e práticas: a relação de professores com os saberes que ensinam. In: REUNIÃO CIENTÍFICA DA ANPED, 26., 2003, Poços de Caldas. Anais... Rio de Janeiro: ANPEd, 2003.

MORETTI, V. D. A articulação entre a formação inicial e continuada de professores que ensinam matemática: o caso da Residência Pedagógica da Unifesp.Educação, Porto Alegre, v. 34, n. 3, p. 385-390, set./dez. 2011.

PARAÍSO, M. Metodologias de pesquisas pós-críticas em educação. Belo Horizonte: Mazza, 2012.

PIMENTA, S. G. O estágio na formação de professores: unidade teoria e prática? 11. ed. São Paulo: Cortez, 2012.

PIMENTA, S. G.; LIMA, M. S. L. Os (des)caminhos das políticas de formação de professores - o caso dos estágios supervisionados e o Programa de iniciação à docência: duas faces da mesma moeda? In: REUNIÃO CIENTÍFICA DA ANPED, 38., 2017, São Luís. Anais... São Luís: Universidade Federal do Maranhão (UFMA), 2017.

REIS, V.; SARTORI, A. S. Educação pública em risco: descontinuidades, golpes e resistência. Espaço do Currículo, João Pessoa, v.11, n.1, p. 59-70, jan./abr.2018. https:// doi.org/10.22478/ufpb.1983-1579.2018v1n11.38004

SANTANA, F. C. M.; BARBOSA, J. C. A relação universidade/escola e o Programa Residência Pedagógica/subprojeto de matemática: estratégias de poder e modos de subjetivação. ReviSeM, v. 4, n. 2, p. 1-24, 2019a. https://doi.org/10.34179/revisem. v4i2.11755

SANTANA, F. C. M. S.; BARBOSA, J. C. O Programa Residência Pedagógica/ subprojeto de matemática e a relação universidade/escola: modos de subjetivação e de resistência. In: ENCONTRO NACIONAL DE EDUCAÇÃO MATEMÁTICA, 13., 2019, Cuiabá. Anais... Cuiabá: SBEM, 2019b.

SILVA, K. A. C. P. Políticas de formação de professores: construindo resistência. Revista Retratos da Escola, Brasília, v. 12, n. 23, p. 307-320, jul./out. 2018. https:// doi.org/10.22420/rde.v12i23.857

SILVA, K. A. C.P.; CRUZ, S. P. A Residência Pedagógica na formação de professores: história, hegemonia e resistências. Momento: Diálogos em Educação, Rio Grande do Sul, v. 27, n. 2, p. 227-247, maio/ago. 2018. https://doi.org/10.14295/momento. v27i2.8062

SILVESTRE, M. A.; VALENTE, W. R. Professores em residência pedagógica: estágio para ensinar matemática. Petrópolis: Vozes, 2014.

SINDICATO NACIONAL DOS DOCENTES DAS INSTITUIÇÕES DE ENSINO SUPERIOR (ANDES). Nota da diretoria do ANDES-Sindicato Nacional sobre o Programa da Residência Pedagógica. ANDES, 2018. Disponível em: https:// www.andes.org.br/conteudos/nota/nota-sobre-o-programa-de-residencia-pedagogica1. Acesso em: 15 abr. 2018.

TARDIF, M. Saberes docentes e formação profissional. 6. ed. Petrópolis: Vozes, 2006. TEIXEIRA, B. R.; CYRINO, M. C. C. T. O estágio de regência como contexto para o desenvolvimento da identidade profissional docente de futuros professores de 
Matemática. Alexandria, Santa Catarina, v. 8, n. 3, p. 131-149, nov. 2015. https://doi. org/10.5007/1982-5153.2015v8n3p131

VEIGA-NETO, A. Anotações sobre as relações entre teoria e prática. Educação em Foco,Juiz de Fora, v. 20, n. 1, p. 113-140, mar./jun. 2015. https://doi.org/10.22195/2447524620152019627

ZEICHNER, K. Repensando as conexões entre a formação na universidade e as experiências de campo na formação de professores em faculdades e universidades. Educação, Santa Maria, v. 35, n. 3, p. 479-504, set./dez. 2010. https://doi. org/10.5902/198464442357

\section{SOBRE OS AUTORES}

Flávia Cristina de Macêdo Santana é doutora em ensino, filosofia e história das ciências pela Universidade Federal da Bahia (UFBA). Professora da Universidade Estadual de Feira de Santana (UEFS).

E-mail: fcmsantana@uefs.br

Jonei Cerqueira Barbosa é doutor em educação matemática pela Universidade Estadual Paulista "Júlio de Mesquita Filho"(UNESP). Professor da Universidade Federal da Bahia (UFBA).

E-mail: jonei.cerqueira@ufba.br

Recebido em 14 de dezembro de 2019 Aprovado em 16 de junho de 2020 